\title{
[THE DIFFERENCE BETWEEN DOCTOR \& ME IS THAT DOCTOR BELIEVES]
}

The difference between Doctor \& me is that Doctor believes in one God \& I

live in fear of many. Sometimes I hear

their lil' music box

$\&$ it is singing to me in Hebrew. Everything

gets black. And gnarly.

Like a cypress knee.

Like all the nude-colored hills of my desert.

(Doctor says they look like the backs of skinned cats,

their shrubbery like leftover acts of fur.)

Sometimes in the night he asks me the Big

Questions, like last night, he says,

Fishhead, what is History?

So I chew it for a long time, until he nearly forgets

me \& falls back asleep. Finally, finally, I say:

Men \& Events. 